\title{
Dynamic Return-Volume Relations in the Saudi Stock Market: Evidence from Quantiles Regressions
}

\author{
Othman Alwagdani ${ }^{1}$ \\ ${ }^{1}$ Department of Economics of Imam Muhammad bin Saud Islamic University, Riyadh, Saudi Arabia \\ Correspondence: Othman Alwagdani, Department of Economics of Imam Muhammad bin Saud Islamic \\ University, P. O. Box 87752, Riyadh 11652, Saudi Arabia. E-mail: Othman.w@gmail.com
}

Received: July 9, 2015

doi:10.5539/ijef.v7n11p84
Accepted: July 29, $2015 \quad$ Online Published: October 25, 2015

URL: http://dx.doi.org/10.5539/ijef.v7n11p84

\begin{abstract}
This paper examines the causality patterns between the lagged trading volume and returns of the Saudi stock market (TASI) for the period from2003:01 to April 2013:05, along with two consecutive sub-periods to account for pre- and post- market collapse of 2006. Using the quantile regression approach, the study finds that the return-volume relations are heterogeneous across quantiles with symmetric tendency across the mean for the full sample period. On the contrary, the study could not support the heterogeneous and symmetric effects for the first sub-sample period. The second sub-sample period is characterized by homogenous across quantiles with statistical evidence of symmetry. Thus, the study concludes that the dependence structure between the lagged volume and subsequent market returns seems to be randomly relying on the chosen period which makes volume unsuitable to be used as explanatory power for returns forecasting.
\end{abstract}

Keywords: quantile, regression, TASI, returns, volume, Saudi

\section{Introduction}

The correlation between trading volume and asset returns, henceforth return-volume relationship, has been treated as an important subject in finance literature. Karpoff (1987) emphasizes that the price-volume relation helps to reveal a better understanding of the financial markets structure with some critical implications for future markets. Understanding the link is essential for portfolio management and provides useful tools for technical analysis since any investment strategy depends on how investors evaluate new information, contained in returns, and attach such information to volume patterns, or as it said in Wall Street "it takes volume to move the price".

Despite voluminous literature in this topic, relatively little attention has been devoted to developing countries especially the Saudi market. The Saudi stock market (TASI) is the largest in the Arab region with market capitalization of $\$ 373.4$ billion in 2012 compared to an average of $\$ 62.4$ billion for the Arab share markets (SAMA, 49th Annual Report). Even with its short history, TASI has experienced interesting developments in terms of regulations and growth especially during the period 2003-2006. For example, this period witnessed the establishment of Capital Market Law as arguably the biggest regulation event in TASI history. In terms of growth, the number of trading volume has tremendously increased to unprecedented levels showing growth of $221 \%$ and $458 \%$ for 2003 and 2006, respectively, whereas market returns showed exceptional performance growing by almost $105 \%$ in 2005 (Table 1). Several factors could attribute to this outstanding performance which causes the biggest bubble in TASI's history. According to SAMA annual report (2006), these factors refer to strong performance of private sector; financial performance of joint-stock companies; the rise of the number of investors; and the increasing oil prices. In addition, one cannot disregard the technological factor which may play a considerable role by exponentially increasing market participants especially after the introduction of Tadawul trading system. These factors pushed the index to reach its highest peak ever at 20,634 points on Feb 25, 2006. After that, the market started to collapse and entered a mainly bearish phase reaching 4,264 points on Nov 23,2008 losing more that $383 \%$ of its peak. 
Table 1. Saudi share market key indicators

\begin{tabular}{lcccc}
\hline \multirow{2}{*}{ Year } & \multicolumn{2}{c}{ Value of Shares Traded (Billion SR) } & \multicolumn{2}{c}{ Share Price Index } \\
\cline { 2 - 5 } & Billion SR & $\%$ & $(1985=1000)$ & $\%$ \\
\hline 2002 & 133.7 & 60 & 2518.08 & 4 \\
2003 & 596.5 & 346 & 4437.58 & 76 \\
2004 & 1773.8 & 197 & 8206.23 & 85 \\
2005 & 4138.7 & 133 & 16712.64 & 104 \\
2006 & 5261.8 & 27 & 7933.29 & -53 \\
2007 & 2557.7 & -51 & 11038.66 & 39 \\
2008 & 1962.9 & -23 & 4802.99 & -56 \\
2012 & 1929.3 & 76 & 6801.20 & 6 \\
\hline
\end{tabular}

For the above consideration, it is essential to understand the market evolution by uncovering patterns of causality between returns and past volume. Thus, this study is an attempt to provide a detailed description of such nexus that might be utilized as explanatory power for stock returns. The process involves exploring the asymmetric nature of returns in facing periods of intensive and low trading volume. The asymmetry indicates that trading volume is lower with price decreases compared to that of price increases. This, in turn, will help to evaluate how traders efficiently observe information and adopt profitable investment strategies by relying on an assumable existing positive causality between volume and subsequent returns. On the other hand, it is possible that most trading are based on non-informational motives adopting herd strategy which can be seen through an existing negative causality. Technically speaking, unfolding the complex link between volume and returns requires going beyond just calculating the average (mean) OLS estimates. Instead, it requires analyzing the dependence progress between volume and return across the quantiles of the returns distribution. To do so, this study applies a quantile regression approach that is flexible enough to capture a variety of effects without further restrictions on coefficients over the quantiles. This makes it feasible to measure how volume could interact with market returns during bearish (low quantile) and bullish (upper quantile) phases.

The findings of this paper are mixed and differ according to the sample periods. For the whole sample, the study finds lower quantiles to exihibit negative values while upper ones associate with positive values. This implies that positive (negative) previous day's value leads to higher (lower) returns of today's returns. This correlation is not robust to the two sub-sample periods which makes past volume a weak candidate for returns forecasting.

The reminder of this paper is orginized as follows. Section 2 provides a brief litrature reviews. Section 3 describes in details the econometric methdology. Section 4 describes the data while section 5 presents the empirical rsults. Section 6 provides concluding remarks.

\section{Litrature Review}

The return-volume relationship attracts the attention of many theoretical and empirical studies. The findings, though, have been mixed with a wide disagreement on the sign and direction of the causality and the preferred statistical methods. Reviewing the disagreement is beyond the scope of this study and, thus, the discussion will be centered on studies that support the link. On the theoretical side, several models support the existence of links between volume and daily price changes of stock markets, e.g. the mixture of distribution hypothesis (Clark, 1973); models of asymmetry in information endowment (Kyle, 1985), and rational expectation and equilibrium models Harris and Raviv (1993) Wang (1994). On the empirical side, the positive link was supported by many studies, e.g. (Karpoff, 1988; MacCarthy \& Najand, 1993; and Kocagil \& Scachmurove, 1998).

Despite strong theoretical and empirical confirmation, the volume-return relationship is still believed to be complex demanding critical choices of appropriate statistical models; types of linearity; and the existence of contemporaneous/lagged effects. In this regard, the focus will be on quantile regression models which I believe is capable of takeing into account all the above factors.

More relevant to this study, Gebka and Wohar (2013) apply OLS and quantile regressions to examine the causality between lagged volume and index returns in the Pacific Basin Countries. While OLS method indicates no causal link, the quantile regressions approach exhibits strong nonlinear causality between volume and returns. Moreover, this causality seems to be non-persistent in nature indicating a limited use to forecast return or support the efficient market hypothesis. The study, also, helps to understand a widely recognized phenomenon by showing how the positive (negative) causality between volume and returns in high (low) quantiles comes in favor of positive volume-volatility causality. 
Chuang, Kuan, and Lin (2009) investigate the casual relations between daily stock returns and volume of NYSE, S\&P 500 and FTSE using quantile regressions. They find some evidence supporting the casual effects of volume on returns that described as heterogeneous across quantiles. The casual effects reveal a spectrum V-shape relation indicating a positive impact of lagged volume on the dispersion of return distribution. Similarly, Lin (2013) applies the quantile regression approach to examine the dynamic stock return-volume relations for six emerging Asian markets. The study finds that the casual effects of volume are heterogeneous across the quantiles with a spectrum of a symmetric V-shape for five of the six countries. Moreover, evidence is found that there is two-way casual relation between stock returns and trading volume in most of the sample countries. The study examines the spillover effects, by including US and Japanese markets to the model, and finds that US return is useful to predict the future returns of all six emerging Asian markets.

Needless to say, a great deal of these studies has been devoted to more advanced markets with more concentration on the US stock markets. Unfortunately, little attention has been paid to emerging market especially the Saudi market. With regards to the Saudi market, Alsubaie and Najand (2009) investigate the relationship between the abnormal change in volume and prices of both individual stocks and portfolios in the Saudi stock market for the period January 1, 1993 to December 31, 2005. They apply the filter-rules-based methodology and the market-adjusted turnover shocks using the ordinary least squares (OLS) and the generalized autoregressive conditional heteroskedasticity (GARCH). They find a reversal in stock returns when conditioned on the changes in past volume. The results are valid for the whole sample, the sub-sample periods, and for both the large- and small-company portfolios. However, the reversal was more pronounced with the loser portfolio when the pressure of the liquidity traders is higher with dropped stock prices. They conclude that lagged volume can be utilized to predict the future Saudi stock prices.

This study contributes to the literature by: (1) understanding the dependence structure of market returns to the lagged trading volume in Saudi Arabia where research on this topic is so rare; (2) instead of relying on the average OLS impact, this study utilizes a more advanced approach by conducting a quantile regression which permits the effects of volume to differ across various quantiles of returns; and (3) this study takes into account different phases of the stock market by dividing the data to several samples according to TASI development.

\section{Methodology}

Let $\mathrm{Y}$ be a dependent variable with probability distribution function $\mathrm{F}$ that defined for $0<\tau<1$ in the quantile function:

$$
Q_{n}(\tau)=\inf \left\{y: F_{n}(y) \geq \tau\right\}
$$

The optimazation problem for the $\tau_{t h}$ conditinal quantile function is defined as:

$$
\begin{aligned}
Q_{n}(\tau) & =\operatorname{argmin}_{\xi}\left\{\sum_{i: Y_{i} \geq \xi} \tau\left|Y_{i}-\xi\right|+\left\{\sum_{i: Y_{i}<\xi}(1-\tau)\left|Y_{i}-\xi\right|\right\}\right. \\
& =\operatorname{argmin} \nabla_{-} \xi \vdash\left\{\sum_{-} i=\rho_{-} \rho_{-} \tau \dashv\left(Y_{-} i-\xi\right)\right\}
\end{aligned}
$$

where $\rho_{\tau}$ is the check function that treats positive and negative values asymmetrically. To account for a quantile regression, a regerrosor $\mathrm{X}$ is added so that the following equation is obtained:

$$
Q\left(\tau \mid X_{i}, \beta(\tau)\right)=X_{i}^{\prime} \beta(\tau)
$$

where $\beta(\tau)$ represts the parameters to be estimated. Equation (3) determines the linear specification between vector $\mathrm{X}$ and the $\tau_{\text {th }}$ conditinal quantile of the response variable $\mathrm{Y}$.

The coefficients $\beta(\tau)$ can be estimated by minimizing the asymmetrically weighted absolute deviations:

$$
\hat{\beta}_{n}(\tau)=\operatorname{argmin}_{\beta(\tau)}\left\{\sum_{i} \rho_{\tau}\left(Y_{i}-X_{i}^{\prime} \beta(\tau)\right)\right\}
$$

To obtain a solution for the coefficients $\hat{\beta}_{n}(\tau)$, the check function must be modified since it is not differentiable at the origin. The modification has been proposed as a linear programming and presented in several studies (see e.g. Buchinsky (1995) and Portnoy and Koenker (1997)). The EVIEWS 7.1 solution is used to compute the conditional quantile $\hat{\beta}_{n}(\tau)$ which is based on a modified version of Koenker and D'orey (1987). The second step in the asymptotic theory is to determine the method by which the coefficient covariance matrices will be computed. According to (Koenker, 2005), the coefficients can be asymptotically normally distributed under some mild regulatory conditions. Koenker and Bassett (1978) show that under the assumption of i.i.d. errors, the asymptotic normality of the estimated regression is as follows: 


$$
\sqrt{n}(\hat{\beta}(\tau)-\beta(\tau)) \sim N\left(0, \tau(1-\tau) s(\tau)^{2} J^{-1}\right)
$$

where:

$$
\begin{gathered}
J=\lim _{n \rightarrow \infty}\left(\sum_{i} X_{i} X_{i}^{\prime} / n\right) \\
S(\tau)=F^{-1 \prime}(\tau)
\end{gathered}
$$

The sparsity function $s(\tau)$ is usually seen as the derivative of the quantile function that contains unknow distribution F. Thus, it is required using a simple difference quotient, as proposed by Siddiqui (1960), to obtain the following sparsity estimation:

$$
\hat{s}(\tau)=\left[\hat{F}^{-1}\left(\tau+h_{n}\right)-\hat{F}^{-1}\left(\tau-h_{n}\right)\right] /\left(2 h_{n}\right)
$$

Finally, the required bandwidth parameter, $h_{n}$, as suggested by Hall-Sheather (1980), takes the form:

$$
h_{-} n=n^{\wedge}(-1 / 3) z_{-} \alpha^{\wedge}(2 / 3)\left(\varangle 1.5\left(\varnothing\left(\Phi^{\wedge}(-1)(\tau)\right)\right) \nabla^{\wedge} 4 /\left(2\left(\Phi^{\wedge}(-1) \square(\tau)\right) \nabla^{\wedge} 2+1\right)\right)^{\wedge}(1 / 5)
$$

where $z_{\alpha}=\Phi^{-1}\left(1-\frac{\alpha}{2}\right)$.

Technically speaking, the least absolute deviation (LAD) estimator of $\hat{\beta}_{n}(\tau)$ is obtained for each of the following quantile $\tau=\{0.1,0.2, \ldots ., 0.9\}$ where $\tau=0.5$ is the median regressor.

To examine the lagged return-volume causality, the study will utilize the following primary regression:

$$
r_{t}=\alpha+\beta \ln v_{t-j}+e_{t}
$$

where $r_{t}$ represent market returns that calculated as $r_{-} t=\ln \left(P_{-} t / P_{-}(t-1)\right) * 100$ where $P_{t}$ is TASI index price, and $\ln v_{t-j}$ is the natural logarithim of past trading volume.

\section{Data}

The data are divided into three panels. Panel (A) covers the whole sample from 1/4/2003 until 4/14/2013; panel (B) represents the period before the market major collapse of 2006 by covering the period 1/4/2003 until 8/5/2006; and panel (C) covers the period after the collapse and lasts from 8/6/2006 to 4/14/2013. Table 2 exhibits the descriptive statistics for return and volume series. The average return is higher during panel (B) which reflects the speculative nature of that era where investors adopted aggressive trading strategies benefiting from the overall bearish trend. On the contrary, Panel (c) shows a negative average return which confirms the risk-average behavior that usually generated after a major collapse. In terms of standard deviation, panel (c) records the highest number which may explain how volatile the period after the collapse. For all panels, Jarque-Bera tests reject the normality of the conditional distributions of volume and returns. Both series during the three panels exhibit negative values for skewness (skewed to the left) along with excess kurtosis. ADF test indicates that both series are stationary at $1 \%$ significance level.

Table 2. Descriptive statistics

\begin{tabular}{lcccccc}
\hline & \multicolumn{2}{c}{ Panel (A) } & \multicolumn{2}{c}{ Panel (B) } & \multicolumn{2}{c}{ Panel (C) } \\
\cline { 2 - 7 } & \multicolumn{2}{c}{$1 / 4 / 2003-4 / 14 / 2013$} & $1 / 4 / 2003-$ & $8 / 5 / 2006$ & \multicolumn{2}{c}{$8 / 6 / 2006-4 / 14 / 22-13$} \\
\cline { 2 - 7 } & Return & Volume & Return & Volume & Return & Volume \\
\hline Mean & 0.037 & 18.271 & 0.222 & 17.043 & -0.061 & 18.928 \\
Median & 0.139 & 18.547 & 0.223 & 17.177 & 0.090 & 18.965 \\
Std. Dev. & 1.702 & 1.111 & 1.287 & 0.740 & 1.880 & 0.603 \\
Skewness & -0.872 & -0.720 & -0.263 & -1.073 & -0.865 & -0.983 \\
Kurtosis & 10.683 & 3.087 & 9.113 & 4.600 & 9.758 & 6.987 \\
Jarque-Bera & 6933 & 232 & 1466 & 279 & 3540 & 1437 \\
Probability & 0.000 & 0.000 & 0.000 & 0.000 & 0.000 & 0.000 \\
\hline Observations & \multicolumn{3}{c}{2681} & \multicolumn{3}{c}{935} \\
\hline
\end{tabular}

\section{Empirical Results}

Following the work of Chuang, Kuan, and Lin (2009), this study connects stock returns and trading volume through estimating the following quantile regression:

$$
r_{t}=a(\tau)+b(\tau) \frac{t}{T}+c(\tau)\left(\frac{t}{T}\right)^{2}+\sum_{j=1}^{q} \alpha_{j}(\tau) r_{-j}+\sum_{j=1}^{q} \beta_{j}(\tau) \ln v_{-j}+e_{t}
$$


where $\mathrm{T}$ represents the sample size and $q \geq 1$. The time factor is added to account for the trending effect in $\ln v_{t}$ as detected in figure (1). The optimal lag length is chosen according on Akaike Information Criterion (AIC) which takes 4 lags for panel (A); 3 lags for panel (B); and 4 lags for panel (C). For simplicity, the lag is set to be the same for both series in each panel. The empirical analysis will be centered on the volume slope coefficient $\left(\beta_{j}\right)$ across the quantiles [0.1 to 0.9]. In addition, OLS results are included to account for the average (mean) impact. To complete the analysis, the symmetric test of Newey and Powell (1987) will be conducted and reported through examining the following null hypothesis:

$$
H_{-} \_:\left(\beta\left(\tau_{-} j\right)+\beta\left(\tau_{-}(k-j-1)\right)\right) / 2=\beta(1 / 2)
$$

where the Wald test is specified under the null hypothesis of symmetry.

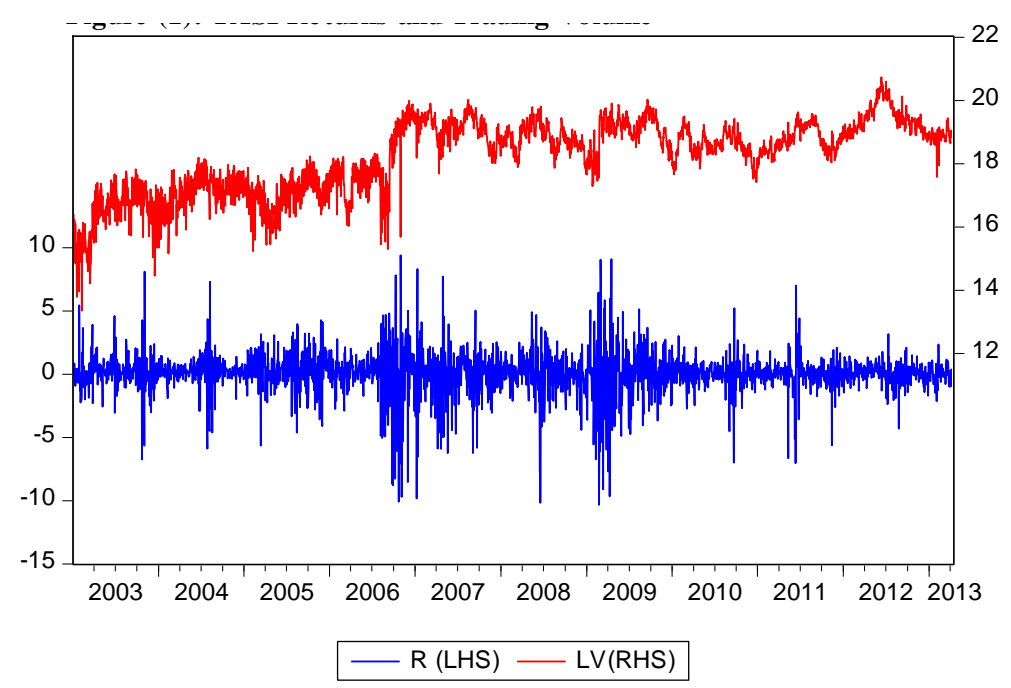

Figure 1. TASI returns and trading volume

\subsection{The Whole Sample (Panel (A): 1/4/2004-4/14/2013)}

The estimated values of the quantile and OLS regressions for panel (A) are presented in Table 3 along with the symmetric test of slope coefficient $\left(\beta_{j}\right)$ for the quantiles [0.1 to 0.9]. It seems that the effects of trading volume are negative and significant for the lower quantiles [0.1- 0.3]; while the effects are positive and significant for the upper quantiles [0.5- 0.9]. The effects appear to be opposite and heterogeneous, (i.e., different values and signs for positive and negative market returns) on both sides of the return distribution with interestingly similar strength. This, in turn, comes in favor of strong return-volume causality with symmetric tendency across the mean as the intensity evolves when market moves from bearish to bullish phases (see Figure 2). The Newey and Powell's test for conditional symmetry indicates that there is a little evidence of departures from symmetry for some sets of quantiles. However, the p-value of the Wald test confirms overall symmetric return-volume relationship across the quantiles. Similarly, it is apparent that symmetric effect do exist for the following quantiles: [0.05, 0.95], [0.3,0.7], and [0.35, 0.65].

Overall, these result come in line with (Gebka \& Wohar, 2013) who find "positive (negative) volume-return causality in high (low) return quantiles" which makes it common phenomenon and not just exclusive to US markets. Theoretically, the observes return-volume relationship is supported by the sequential information model (copeland, 1976; Jennings, 1983) where information disseminates sequentially among market participants. However, the persistent nature of volume effects confirm its usefulness to be used as a forecasting tool for market returns which violate the efficient market hypothesis. 
Table 3. Estimates of quantile and OLS regression, and symmetric tests for panel (A)

\begin{tabular}{lccccc}
\hline & Quantile Regression Estimates & \multicolumn{3}{c}{ Symmetric Tests for The Slopes } \\
\hline Quantile & Coefficient & Prob. & Quantiles & Restr. Value & Prob. \\
\hline 0.100 & -0.587 & 0.000 & {$[0.05,0.95]$} & -0.399 & 0.052 \\
0.200 & -0.249 & 0.000 & {$[0.1,0.9]$} & -0.300 & 0.003 \\
0.300 & -0.095 & 0.007 & {$[0.15,0.85]$} & -0.208 & 0.005 \\
0.400 & -0.005 & 0.835 & {$[0.2,0.8]$} & -0.100 & 0.069 \\
0.500 & 0.064 & 0.009 & {$[0.25,0.75]$} & -0.083 & 0.063 \\
0.600 & 0.102 & 0.0001 & {$[0.3,0.7]$} & -0.060 & 0.101 \\
0.700 & 0.163 & 0.000 & {$[0.35,0.65]$} & -0.064 & 0.025 \\
0.800 & 0.277 & 0.000 & {$[0.4,0.6]$} & -0.032 & 0.156 \\
0.900 & 0.415 & 0.000 & {$[0.45,0.55]$} & -0.023 & 0.142 \\
OLS & -0.059 & 0.179 & Wald Test & 96.725 & 0.000 \\
\hline
\end{tabular}

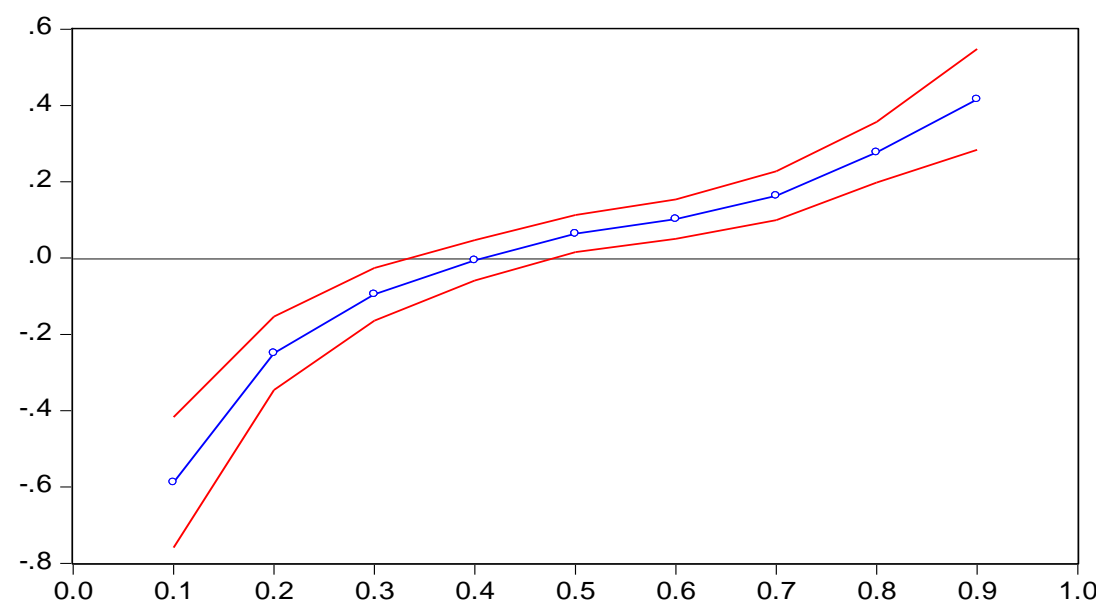

Figure 2. Quantile process estimates $(95 \% \mathrm{CI})$ for whole sample

\subsection{The First Sub-Sample Period (Panel (B): 1/4/2004-8/5/2006)}

With the exception of the lower quantiles [0.1- 0.5], Table 4 demonstrates positive but insignificant return-volume relationships for all quantiles in the sets [0.1- 0.9]. Similarly, OLS estimate could not provide a solid evidence of average impacts of volume on returns. With regards to symmetry, Figure 3 shows the slope values of regressing TASI returns against its trading volume across the quantiles which, with the Wald test, confirm the marginal asymmetric return-volume link. The asymmetric effects can also be seen for all set of quantiles implying that the structure of interaction is more pronounced with lower tail dependence and upper tail independence (Mensi et al., 2014). In fact the positive but relatively weak return-volume causality is clustered around the mean and not randomly scattered, as seen in the full sample panel, implying that market makers during this sub-period are not active enough to control the market trend compared to liquidity traders who are the driving force in creating market booms. Empirically, the lack of solid relationship between volume and returns can be seen in several studies e.g., Lee and Rui (2002) and Gebka (2012). Thus, volume is not useful to be used as an explanatory power for stock returns. Most traders follow non-informational strategies which lead to ignoring publically-available information, such as past volume, and adopting herd behavior which could partially inflate to fuel the market bubble.

Table 4. Estimates of quantile and OLS regression, and symmetric tests for panel (B)

\begin{tabular}{lccccc}
\hline & Quantile Regression Estimates & \multicolumn{3}{c}{ Symmetric Tests for The Slopes } \\
\hline Quantile & Coefficient & Prob. & Quantiles & Restr. Value & Prob. \\
\hline 0.1 & 0.114 & 0.337 & {$[0.05,0.95]$} & -0.263 & 0.441 \\
0.2 & 0.157 & 0.052 & {$[0.1,0.9]$} & -0.050 & 0.760 \\
0.3 & 0.082 & 0.197 & {$[0.15,0.85]$} & 0.136 & 0.304 \\
0.4 & 0.051 & 0.321 & {$[0.2,0.8]$} & 0.139 & 0.180 \\
\hline
\end{tabular}




\begin{tabular}{|c|c|c|c|c|c|}
\hline 0.5 & 0.045 & 0.372 & {$[0.25,0.75]$} & 0.094 & 0.281 \\
\hline 0.6 & 0.030 & 0.585 & {$[0.3,0.7]$} & 0.017 & 0.808 \\
\hline 0.7 & 0.025 & 0.697 & {$[0.35,0.65]$} & 0.090 & 0.113 \\
\hline 0.8 & 0.072 & 0.403 & {$[0.4,0.6]$} & -0.009 & 0.835 \\
\hline 0.9 & -0.075 & 0.549 & {$[0.45,0.55]$} & 0.006 & 0.857 \\
\hline OLS & -0.002 & 0.975 & Wald Test & 36.046 & 0.827 \\
\hline
\end{tabular}

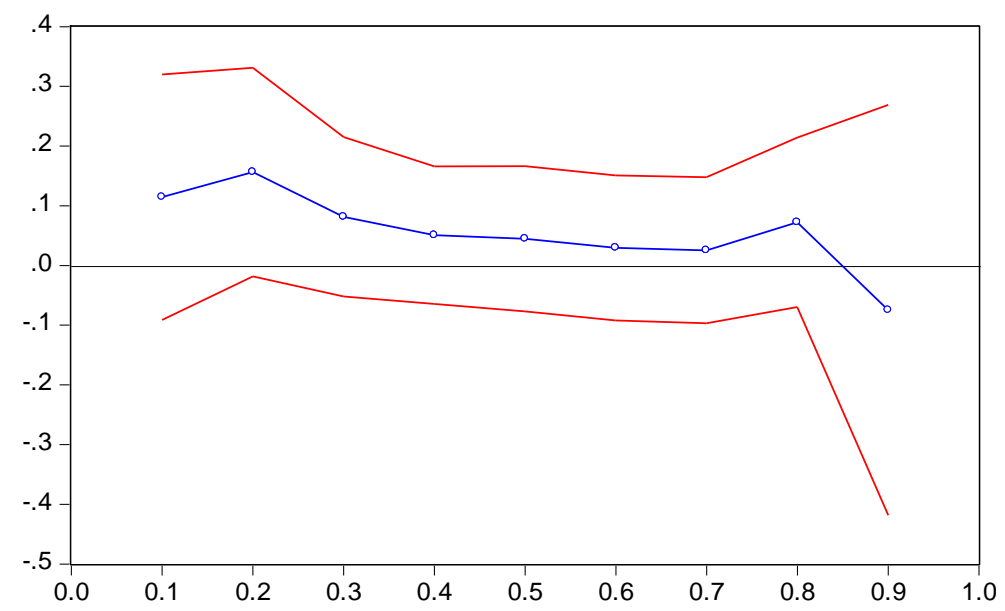

Figure 3. Quantile process estimates (95\% CI) for subperiod (1)

\subsection{The Second Sub-Sample Period (Panel (C): 8/6/2006-4/14/2013)}

Table 5 combines the coefficients results of the quantile regression estimates, OLS slope and symmetric conditional tests. The results confirm a significant positive return-volume relationship across the quantiles, expect for $\tau=0.1$ and 0.9. The effects appear to cluster around the mean with symmetric tendency as seen in Figure 4. The Wald test confirms the existence of overall symmetric effects which means that the average value of two sets of the coefficients around the median must be the same as the value of the coefficients at the median. Similarly, the p-values confirm that most quantiles sets have symmetric effects which validate the lagged impact of volume on market returns.

All in all, the casual impact of past volume on returns depends on the trading motives and how information disseminates among market traders. According to Gebka and Wohar (2013), the arrivals of good private information will create intensive trading volume at $\mathrm{t}-1$ which leads to higher prices at $\mathrm{t}-1$ and eventually creates higher returns at $\mathrm{t}$ causing a positive causality between volume and subsequent returns. By the same token, negative private information causes a negative causality since it generates higher volume at $t-1$ pushing prices down at $\mathrm{t}-1$ and eventually leads to lower returns at $\mathrm{t}$. On the other hands, non-informational traders can influence the future trends through their decision of selling or buying. If they decide to sell after intensive volume then prices will decrease at $\mathrm{t}-1$ but the market will re-adjust prices according to their fundamental values which creates a positive return at $\mathrm{t}$. However, if non-informational traders decide to buy at time t-1, after higher volume, this will create higher prices at $t$ but then prices revert to their fair values at time $t$ creating a negative return-volume link. The above analysis is a guideline to provide an intuitive explanation for powers that influence the magnitude and direction of the link between volume and returns of TASI throughout the study samples and it can be summarized in Table 6 .

Table 5. Estimates of quantile and OLS regression, and symmetric tests for panel (C)

\begin{tabular}{lccccc}
\hline & Quantile Regression Estimates & \multicolumn{3}{c}{ Symmetric Tests for The Slopes } \\
\hline Quantile & Coefficient & Prob. & Quantiles & Restr. Value & Prob. \\
\hline 0.1 & -0.078 & 0.509 & {$[0.05,0.95]$} & -0.542 & 0.010 \\
0.2 & 0.076 & 0.300 & {$[0.1,0.9]$} & -0.343 & 0.015 \\
0.3 & 0.098 & 0.075 & {$[0.15,0.85]$} & -0.194 & 0.066 \\
0.4 & 0.165 & 0.001 & {$[0.2,0.8]$} & -0.110 & 0.201 \\
0.5 & 0.134 & 0.002 & {$[0.25,0.75]$} & -0.044 & 0.541 \\
\hline
\end{tabular}




\begin{tabular}{lllccc}
\hline 0.6 & 0.093 & 0.030 & {$[0.3,0.7]$} & -0.037 & 0.532 \\
0.7 & 0.133 & 0.008 & {$[0.35,0.65]$} & -0.015 & 0.762 \\
0.8 & 0.082 & 0.195 & {$[0.4,0.6]$} & -0.011 & 0.781 \\
0.9 & 0.003 & 0.974 & {$[0.45,0.55]$} & 0.001 & 0.967 \\
OLS & 0.140 & 0.067 & Wald Test & 190.041 & 0.000 \\
\hline
\end{tabular}

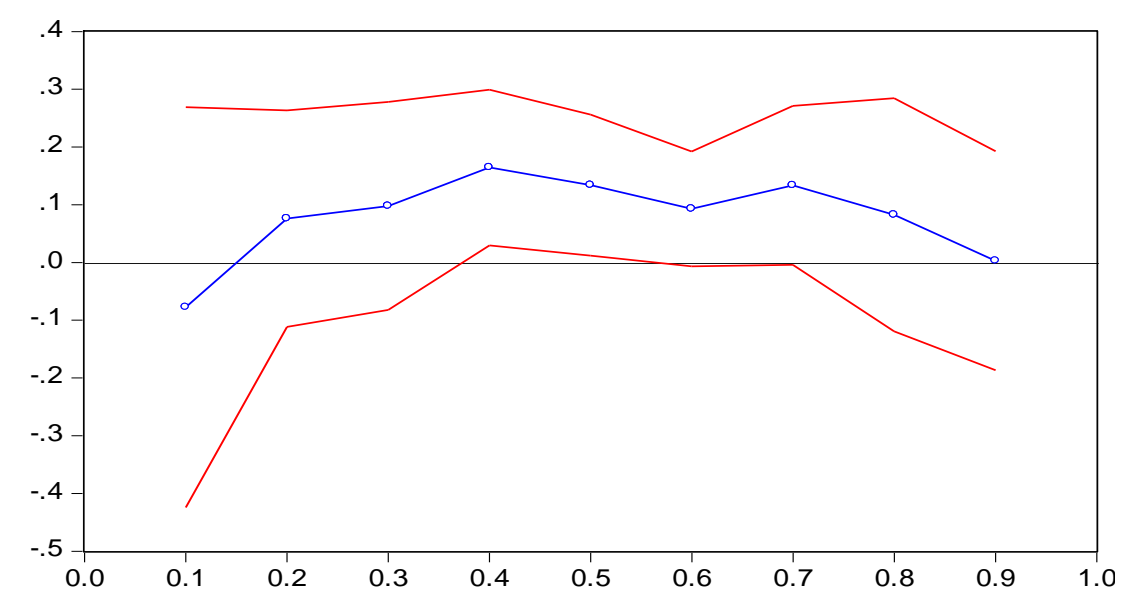

Figure 4. Quantile process estimates (95\% CI) for subperiod (1)

Table 6. Volume-return causality and the prevailing trading strategy

\begin{tabular}{lcc}
\hline Panel & Prevailing Trading Strategy & Type of causality \\
\hline (A) & $\begin{array}{c}\text { (Good/Bad) Private Information Trading } \\
\text { (Buy/Sell)Non-informative Trading }\end{array}$ & Positive \\
& Negative \\
\hline (B) & (Sell) Non-informative Trading & (Weak) Positive \\
\hline (C) & (Sood) Private Information Trading & Positive \\
& & \\
\hline
\end{tabular}

\section{Conclusion}

Modeling the return-volume causality is important for portfolio managers and market participants. It helps to uncover the patterns by which new information contained in volume can predict future subsequent returns. In addition to its importance, the causality is very complex with a wide theoretical and empirical disagreement on the direction and magnitude of such effects. Instead of relying on the average impact (OLS), this study examines the effects of past volume across different quantiles of the returns distribution by utilizing the quantile regression approach. This technique is flexible enough to provide a more detailed description of the link through calculating the responses of the returns to external shocks by assuming different threshold values instead of just the average response. The time frame of this research is carefully chosen through dividing the data into two consecutive sub-periods to take into account the periods before and since the market collapse of 2006. The findings are interesting and can be interpreted within theoretical frameworks. For the full sample period, the lagged effects of volume on subsequent returns of TASI are heterogeneous across quantiles with symmetric co-movement as TASI moves from bearish to bullish market. This comes in line with Chuang et al. (2009) as the linear effect of volume is positive for high future returns and negative for low future returns. For this period, the dependence structure of returns is motivated by private information as well as non-informational trading strategies as argued by Gebka and Whohar (2013). The results, however, are mixed across the sub-period. For the first sub-period, the effects are homogenous and clustered around the mean with no evidence of symmetry. Non-informational buy strategy seems the prevailing trading motive which can justify the herding behavior that shapes the pre-collapse stage. For the second sub-period, however, the effects of the lagged volume are symmetric and homogenous supporting the positive volume-return nexus.

Since the results vary across different sample periods, they bear no practical implications on using past volume to predict future sub-returns. However, further future studies may include non-linear elements that could explore different aspects of the causality patterns. 


\section{References}

Alsubaie, A., \& Najand, M. (2009). Abnormal Trading Volume and Autoregressive Behavior in Weekly Stock Returns in the Saudi Stock Market. Emerging Markets Review, 10, 207-225. http://dx.doi.org/10.1016/j.ememar.2009.06.001

Buchinsky, M. (1995). Estimating the Asymptotic Covariance Matrix for Quantile Regression Models: A Monte Carlo Study. Journal of Econometrics, 68, 303-338. http://dx.doi.org/10.1016/0304-4076(94)01652-G

Chuang, C. C., Kuan, C. M., \& Lin, H. Y. (2009). Causality in Quantiles and Dynamic Stock Returns-Volume Relations. Journal of Banking and Finance, $1351-1360$. http://dx.doi.org/10.1016/j.jbankfin.2009.02.013

Clark, P. (1973). A Subordinated Stochastic Process Model with Finite Variance for Speculative Prices. Econometrica, 41, 135-155. http://dx.doi.org/10.2307/1913889

Copeland, T. (1976). A model of Assets Trading under the Assumption of Sequential Information Arrival. Journal of Finance, 31, 1149-1168. http://dx.doi.org/10.2307/2326280

Gebka, B. (2012). The dynamic relation between returns, trading volume, and volatility: Lessons from spillovers between Asia and the United States. Bulletin of Economic Research, 64, 65-90. http://dx.doi.org/10.1111/j.1467-8586.2010.00371.x

Gebka, B., \& Wohar, M. (2013). Causality between Trading Volume and Returns: Evidence from Quantile Regressions. International Review of Economics and Finance, 27, 144-159. http://dx.doi.org/10.1016/j.iref.2012.09.009

Hall, P., \& Simon, J. S. (1980). On the Distribution of the Studentized Quantile. Journal of the Royal Statistical Society, Series B, 50(3), 381-391.

Harris, M., \& Raviv, A. (1993). Differences of Opinion Make A Horse Race. Review of Financial Studies, 6, 473-506. http://dx.doi.org/10.1093/rfs/5.3.473

Jennings, R., \& Barry, C. (1983). Information Dissemination and Portfolio Choice. Journal of Financial and Quantitative Analysis, 18, 1-19. http://dx.doi.org/10.2307/2330801

Karpoff, J. M. (1988). Costly Short Sales and the Correlation of Returns with Volume. The Journal of Financial Research, 11(3), 173-188. http://dx.doi.org/10.1111/j.1475-6803.1988.tb00080.x

Karpoff, J. M. (1987). The Relation between Price Changes and Trading Volume: A Survey. Journal of Financial and Quantitative Analysis, 22, 109-126. http://dx.doi.org/10.2307/2330874

Kocagil, A., \& Shachmurove, Y. (1998). Return-Volume Dynamics in Futures Markets. The Journal of Futures $\begin{array}{lll}\text { Market, } & \text { 38(4), }\end{array}$ http://dx.doi.org/10.1002/(SICI)1096-9934(199806)18:4<399::AID-FUT3>3.0.CO;2-U

Koenker, R. (2005). Quantile Regression. New York: Cambridge University Press. http://dx.doi.org/10.1017/CBO9780511754098

Koenker, R., \& Gilbert, B. J. (1978). Regression Quantiles. Econometrica, 46(1), 33-50. http://dx.doi.org/10.2307/1913643

Koenker, R. W., \& Vasco, D’O. (1987). Algorithm AS 229: Computing Regression Quantiles. Applied Statistics, 36(3), 383-393. http://dx.doi.org/10.2307/2347802

Kyle, A. (1985). Continuous Auctions and Insider Trading. Econometrica, 53, 1315-1335. http://dx.doi.org/10.2307/1913210

Lee, C. F., \& Rui, O. M. (2000). Does trading volume contain information to predict stock returns? Evidence from China's stock markets. Review of Quantitative Finance and Accounting, 14, 341-360. http://dx.doi.org/10.1023/A:1008319826042

Lin, H. Y. (2013). Dynamic Stock Return-Volume Relation: Evidence from Emerging Asian Markets. Bulletin of Economic Research, 65(2), 0307-3378. http://dx.doi.org/10.1111/j.1467-8586.2011.00428.x

McCarthy, J., \& Najand, M. (1993). State Space Modelling of Price and Volume Dependence: Evidence from Currency Futures. Journal of Futures Market, 13, 335-344. http://dx.doi.org/10.1002/fut.3990130402

Mensi, W., Hammoudah, S., Reboredo, J. C., \& Nguyen, D. K. (2014). Do Global Factors Impact Stock Markets? A Quantile Regression Approach. Emerging Markets Review, 19, 1-17. 
http://dx.doi.org/10.1016/j.ememar.2014.04.002

Newey, W., \& James, L. P. (1987). Asymmetric Least Squares Estimation. Econometrica, Series, 55(3), 819-847. http://dx.doi.org/10.2307/1911031

Portnoy, S., \& Roger, K. (1997). The Gaussian Hare and the Laplacian Tortoise: Computability of Squared-Error $\begin{array}{lllll}\text { versus } & \text { Absolute-Error } \quad \text { Estimators. } & \text { Statistical } & \text { Science, } & 12(4),\end{array}$ http://dx.doi.org/10.1214/ss/1030037960

Saudi Arabian Monetary Agency (SAMA). (n. d.). Various Annual Bulletins.

Siddiqui, M. M. (1960). Distribution of Quantiles in Samples from a Bivariate Population. Journal of Research of the National Bureau of Standards-B, 64(3), 145-150. http://dx.doi.org/10.6028/jres.064B.017

Wang, J. (1994). A Model of Competitive Stock Trading Volume. Journal of Political Economy, 102, $127-168$. http://dx.doi.org/10.1086/261924

\section{Copyrights}

Copyright for this article is retained by the author(s), with first publication rights granted to the journal.

This is an open-access article distributed under the terms and conditions of the Creative Commons Attribution license (http://creativecommons.org/licenses/by/3.0/). 